\title{
Stability analysis of cutting high loess slope
}

\author{
Lin Ma \\ Shanxi Transportation Research Institute, Key Laboratory of Highway Construction \& Maintenance Technology in Loess \\ Region, Ministry of Transport,Taiyuan,030006 \\ 327759595@qq.com
}

\begin{abstract}
Slope stability is the focus of attention in geotechnical. The cutting loess slope because of its high slope and soil properties makes the research question becomes complicated. through the investigation The paper selected typical cutting loess high slope to study, and analyzed slope stability under different factors using strength reduction . Studies have shown that plastic zone of loess slope increased with cohesion. Safety factor increases with cohesion increasing and it decreases with slope angle increasing.
\end{abstract}

Keywords- high loess slope; cohesion; friction angle; slope angle; stability

\section{INTRODUCTION}

Slope stability is one of the three classic problems of soil mechanics[1]. Loess distributed widely in northwest and north of China. Loess is with large pores, collapsible large deformation, structural[2] and other features, making loess slope program under scrutiny. Loess slope mainly because of its high slope and soil properties make frequent partial or whole landslides when it encountered in external loads. It causes huge losses to the national economy and people's lives and property.

Due to the complexity of high loess slope failure mechanism, stability in a reasonable analysis of high loess slope is still the focus and difficult currently. At present, analysis methods of slope stability are mainly limit equilibrium slice method, limit analysis method, finite element fat[3-6], strength reduction[7-9], etc. Because of the traditional limits analytical methods can not automatically search for the sliding surface and the corresponding stability safety factor, you must know the location and shape of the sliding surface, and can not consider completely soil stress-strain relationship. The strength reduction does not need to assume the shape of the sliding surface. It can be directly strike the slope safety

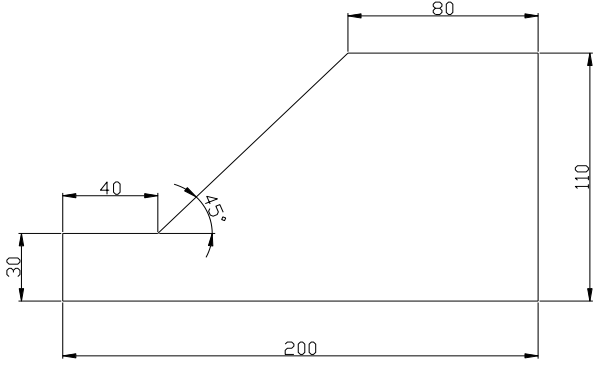

(a) schematic model(unit: m) factor and the approximate location of landslide. With the help of the finite difference software FLAC3D, the paper used strength reduction on a high slope loess Shanxi to numerical simulation, then evaluated high loess slope stability under various factors.

\section{StREnGth Reduction MethoD}

Strength reduction is a method of calculating the safety factor in the slope stability analysis. The method of determining the safety factor is the degree of soil shear strength was reduction when the slope just reached the critical failure state. Highlights of strength reduction is the use of the formula (1) and (2) to adjust the soil strength parameters $\mathrm{c}$ and $\varphi$, then analyzed the slope stability, continue to increase the reduction factor, repeated calculations, until it reaches a critical damage, then the resulting reduction factor is the safety factor Fs.

$$
\begin{gathered}
c_{F}=c / F_{\text {trial }} \\
\varphi_{F}=\tan ^{-1}(\tan \varphi) / F_{\text {trial }}
\end{gathered}
$$

In formula $c_{F}$ is cohesion after reduction, $\varphi_{F}$ is friction angle after reduction and $F_{\text {trial }}$ is reduction factor.

\section{SLOPE CALCULATION MODEL}

The paper selects high loess slope in Shanxi for the study. The slope height is taken as 80 meters. the slope toe is $45^{\circ}$.Then established calculation model accordance with plane strain problems. Since the model size has some effect on the results, take the from the slope foot to the left border is 40 meters. The distance from slope top to the right border is 80 meters. The slope toe extends downward 20 meters. Model shows in Fig .1.The slope calculate parameters obtained under laboratory test, as shown in table 1 .

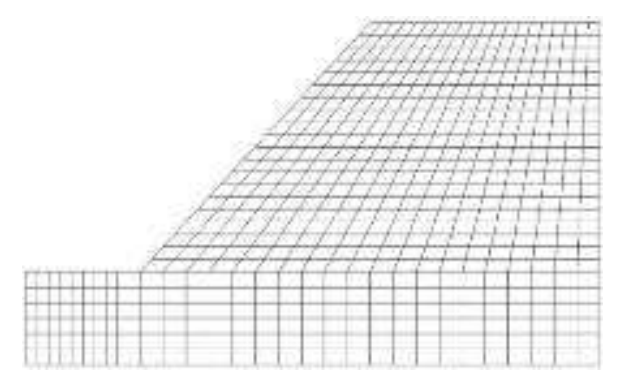

(b) numerical grid model

Figure 1. slope calculation model 
TABLE I . SOIL SLOPE PARAMETER TABLE

\begin{tabular}{l} 
type Natural Density $\left(\mathrm{g} / \mathrm{cm}^{3}\right)$ Elastic Modulus(MPa) \\
\hline soil 1.85 \\
\hline IV. HIGH SLOPE STABILITY EVALUATION OF THE IMPACT \\
INDICATORS \\
The horizontal displacement and shear strain \\
increment are two more important factors in slope stability \\
analysis. Its value distribution is a direct reflection of the \\
slope stability rating. The paper analyzed horizontal \\
displacement cloud and shear strain increment cloud by \\
calculating stability of high loess slope in Shanxi. Safety \\
factor is 1.13 . \\
According to Fig .2, there is a clear potential slope \\
sliding surface under its own weight stress field. The \\
entire surface of the slope is movement trends to the \\
airport surface. Fig .3 confirms this law better. The main \\
reason is that this slope located in Q2 loess formations. It \\
is of high strength and a certain self-supporting capacity. \\
However, the safety factor is small compared to the \\
provisions in "building slope engineering technical \\
specifications" GB50330-2002 [10]. So it should deal with \\
its slope to prevent accidents.
\end{tabular}



Figure 2. slope horizontal displacement cloud

\begin{tabular}{ccc} 
Poisson's ratio & Cohesion $(\mathrm{kPa})$ & $\begin{array}{c}\text { Friction } \\
\text { angle }\left({ }^{\circ}\right)\end{array}$ \\
\hline 0.3 & 60 & 28.5 \\
\hline
\end{tabular}

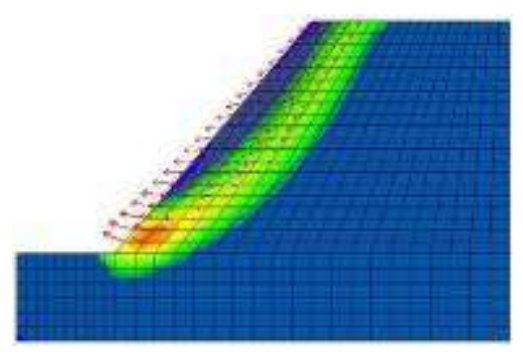

Figure 3. slope shear strain increment cloud

According to Fig .2, there is a clear potential slope sliding surface under its own weight stress field. The entire surface of the slope is movement trends to the airport surface. Fig .3 confirms this law better. The main reason is that this slope located in Q2 loess formations. It is of high strength and a certain self-supporting capacity. However, the safety factor is small compared to the provisions in "building slope engineering technical specifications" GB50330-2002 [10]. So it should deal with its slope to prevent accidents.

High loess slope failure mechanism is complex and impact indicators are so many that it should be quantitative evaluation of its stability one by one when analyzing in order to reveal the complexity of the failure mechanism of high loess slope. According to statistics, Shanxi loess soil properties shows that the changes scope of cohesion is $15 \mathrm{kPa} \sim 70 \mathrm{kPa}$, friction angle is $15^{\circ} \sim 30^{\circ}$, Elastic Modulus is $50 \mathrm{MPa} \sim 320 \mathrm{MPa}$ and the slope toe is $30^{\circ} \sim 82^{\circ}$. So take the value of different factors are shown in table 2 .

TABLE II. THE VALUE TABLE OF DIFFERENT FACTORS HIGH LOESS SLOPE

\begin{tabular}{ccccc}
\hline factors & Level 1 & Level 2 & Level 3 & Level 4 \\
\hline cohesion & $18 \mathrm{kPa}$ & $25 \mathrm{kPa}$ & $40 \mathrm{kPa}$ & $60 \mathrm{kPa}$ \\
\hline friction angle & $16.5^{\circ}$ & $20.5^{\circ}$ & $24.5^{\circ}$ & $28.5^{\circ}$ \\
\hline slope toe & $30^{\circ}$ & $45^{\circ}$ & $60^{\circ}$ & $75^{\circ}$ \\
\hline
\end{tabular}

A. cohesion indicators

Slope failure damage can be seen as the process that the plastic zone developed progressively and expanded until it connected and fully flow up the plastic state, finally it can't continue to bear the load. Different slope intensity inevitably produced different plastic deformation in the slope of the part region, as shown in Fig .4. 


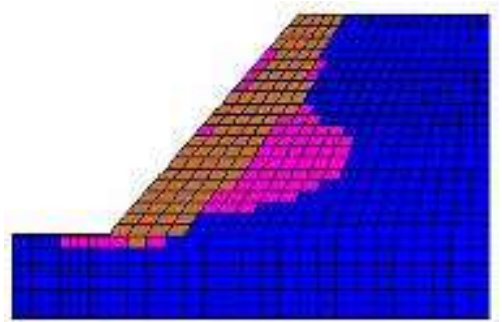

(a) cohesion is $18 \mathrm{kPa}$

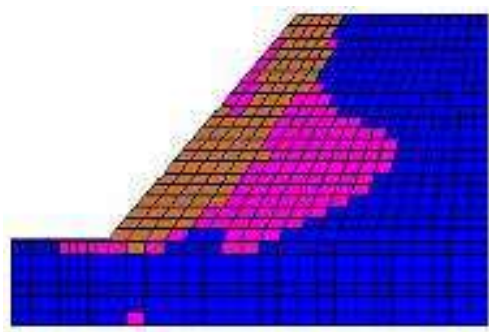

(b) cohesion is $25 \mathrm{kPa}$

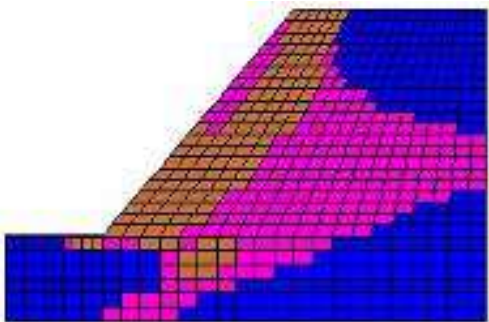

(c) cohesion is $40 \mathrm{kPa}$

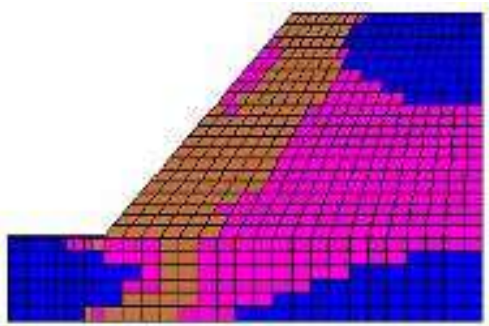

(d) cohesion is $60 \mathrm{kPa}$

Figure 4. slope plastic figure under different cohesion

TABLE III. SLOPE SAFETY FACTOR UNDER DIFFERENT COHESION

\begin{tabular}{rcccc}
\hline cohesion $/ \mathrm{kPa}$ & 18 & 25 & 40 & 60 \\
\hline safety factor/Fs & 0.83 & 0.89 & 1 & 1.13 \\
\hline
\end{tabular}

It is difficult to find that the slope plastic zone increases with cohesion increasing at the same reduction factor. The reason is due to magnitude is bigger when a reduction of large cohesion value. Resulting that the soil occurs in a sharp deformation and failure when it has not reached stress equilibrium. Sphere of influence is larger.

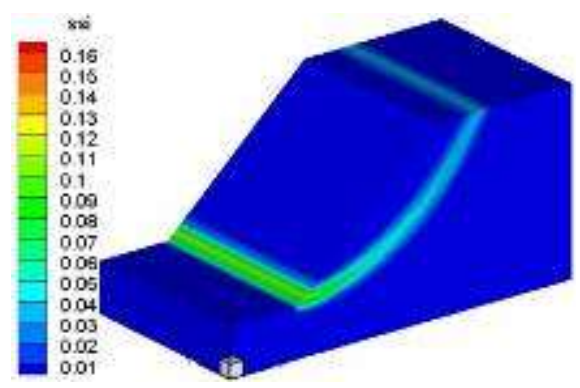

(a) $\varphi=16.5^{\circ}$



(b) $\varphi=20.5^{\circ}$
At the same time the safety factor of the slope increases with cohesion increasing.

\section{B. friction angle indicators}

Friction angle is an important indicator of strength. The value changes will cause deformation of the soil. The paper studied the shear strain increment changes under different friction angle of slope, as shown in Fig .5.



(c) $\varphi=24.5^{\circ}$

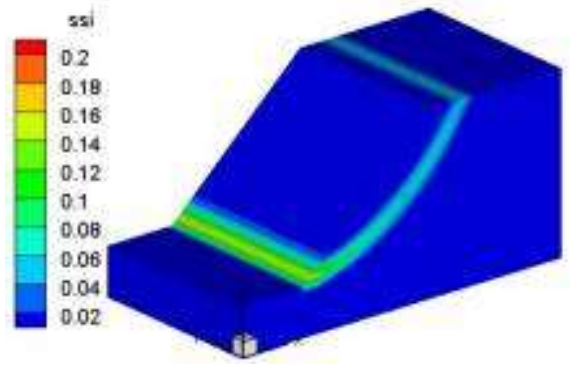

(d) $\varphi=28.5^{\circ}$

Figure 5. slope shear strain contours under different friction angles 
TABLE IV. SLOPE SAFETY FACTOR UNDER DIFFERENT FRICTION ANGLES

\begin{tabular}{lllll}
\hline Friction angle $/^{\circ}$ & 16.5 & 20.5 & 24.5 & 28.5 \\
\hline Safety factor/Fs & 0.77 & 0.89 & 1.01 & 1.13 \\
\hline
\end{tabular}

As can be seen from Fig .5, slope has shown a significant sliding belt under four friction angle. And shear strain increment decreases with friction angle increasing. The reason is that slope strength is small when the friction angle is lower, the likelihood of its occurrence damage is larger. In the history of sedimentation deformation is also large. Shear strain increment is large at the same other conditions. The slope safety factor increases with the friction angle increasing. When the friction angle


increased from $16.5^{\circ}$ to $28.5^{\circ}$, safety factors increased from 0.77 to 1.13 , an increase is $46.8 \%$.

\section{C. $\quad$ slope angles indicators}

When the slope stability analysis, the impact on the stability of slope type[11] is more important. This paper studies the slope stability conditions when the slope angle is respectively $30^{\circ}, 45^{\circ}, 60^{\circ}, 70^{\circ}$, then examining changes in the level of their displacement. There are shown in Figure 7.

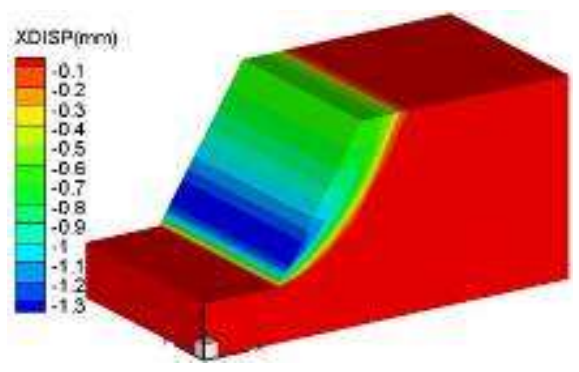

(c) $\beta=60^{\circ}$

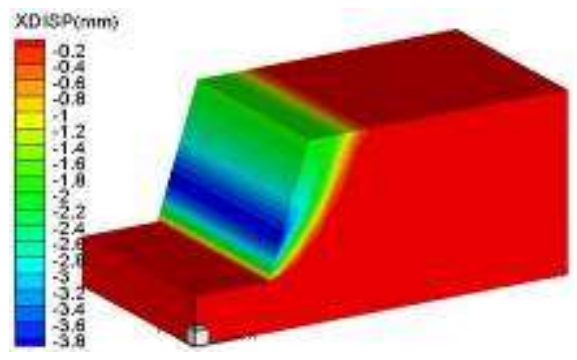

(d) $\beta=75^{\circ}$

(b) $\beta=45^{\circ}$

Figure 6. slope horizontal displacement contours of different slope angle

TABLE V . SAFETY FACTOR UNDER DIFFERENT SLOPE ANGLES

\begin{tabular}{ccccc}
\hline slope angle/ $^{\circ}$ & 30 & 45 & 60 & 75 \\
\hline safety factors/Fs & 1.57 & 1.13 & 0.88 & 0.72 \\
\hline
\end{tabular}

According to Fig .6, the horizontal displacement of the slope gradually increases with the slope angle increasing. Its safety and stability decreases. The safety factor gradually decreased, as shown in table 5. In slope protection and design it should consider the impact of shelving and need to take support when necessary.

\section{IN CONCLUSION}

Security and stability loess slope are related to livelihood, they are also the focus of geotechnical industry. The paper analyzed the security and stability of high loess slope using strength reduction through numerical simulations, the following conclusions are given.

(1) Plastic zone of loess slope increased with cohesion. Safety factor increases with cohesion increasing.
(2) Safety factor decreases with slope angle increasing. In slope protection and design it should take support when necessary.

\section{REFERENCES}

[1] Li Guangxin. Advanced Soil Mechanics[M]. Peking, Tsinghua University Press, 2004.

[2] Liu Zudian. Loess Mechanics and Engineering[M]. Shaanxi Science and Technology Press,1997.

[3] Zheng Yinren. FEM Limit Analysis and Its Application in Slope[M]. China Communications Press,2011.

[4] Chen Lihua, Jin Xiaoguang. Study on the applicability of three criteria for slope instability using finite element strength reduction method[J]. CHINA CIVIL ENGINEERING JOURNAL, 2012, Vol.45(9), pp:136-146. 
[5] Zhao Jie, Shao Longtan. Research of FEM stability analysis of soil Nailing support for foundation pit[J]. Rock and Soil Mechanics, 2008, Vol.29(6),pp:1654-1658.

[6] Hai Long, Liang Bing. Analysis of land slope stablility considering rainfall infiltration[J]. Journal of Water Resources and Water Engineering, 2010, Vol.21(4),pp: 46-50.

[7] Ma Jianxun, Nai Zhisheng. 3D FEM analysis of slope stability based on strength reduction method[J]. Rock Mechanics and Engineering, 2004, 23(16),pp: 2690-2693.

[8] Yang Guanghua, Zhong Zhihui, Zhang Yucheng. Slope stability analysis by local strength reduction method[J]. 2010,Vol.31(S2),pp:53-58.
[9] Zhao Shangyi, Zheng Yingren, Wang Jiahua. Discussion on calculation method of slope rock-soil lateral pressure based on factor of safety with strength reduction[J]. Chinese Journal of Rock Mechanics and Engineering, 2010,Vol.29(9),pp:1-7.

[10] Building slope engineering technical specifications-GB50330-2002[M]. Ministry of Housing and Urban-Rural Development of the People's Republic of China, 2002.

[11] Deng Xiaopeng. The Construction Method of Highway Waste Residue as Subgrade Filler[J]. Shanxi science and technology of communications, 2012, Vol.214(1),pp:25-26. 